\title{
The Impact of Artificial Intelligence Techniques on the Entrepreneurship of the Leadership of International Business Organizations - A Suggested Model - An Analytical Study
}

\author{
Dr. Tharwat Alhawamdeh Vice Dean, PhD, Associate Prof \\ School of Business, Jerash University \\ Jerash University, Jerash, Jordan \\ Mohammad Omar Alzoubi ${ }^{1}$, PhD, Prof. \\ School of Business, Jerash University \\ Jerash University, Jerash, Jordan
}

\begin{abstract}
Entrepreneurial leadership with a pure intellectual starting point has received the attention of high-quality international business organizations because of its need for leadership that possesses strategic thinking which can change with the changing circumstances surrounding it, hence the interest in the topic of entrepreneurial leadership with strategic thinking due to the acceleration of the complex environmental conditions surrounding these organizations, represented by the emergence of the phenomenon of globalization and the cognitive economy and technological progress, which may be represented here as the techniques of artificial intelligence, which prompted these leaders and their organizations to search for mechanisms for their continuity and stability in a competitive world. Therefore, it is expected that entrepreneur leaders possess the qualities of intellectual stimulation, which is an important matter in entrepreneurial leadership, and that they are also ready to change the existing status of their organizations by creating major changes, through taking advanced technological technologies. This is expected to help them achieve the visions of their organizations to reach local and global entrepreneurship. Therefore, the current study worked on knowing the impact of artificial intelligence on the entrepreneurship of the leadership of international business organizations to reach the added value of its strategic operations at the local and global levels.
\end{abstract}

Keywords:- Artificial intelligence, Entrepreneurship, International business organizations.

\section{INTRODUCTION}

The permanent development of the leadership process is due to the relentless pursuit of international business organizations to confront the unknown and the unexpected events, and this requires strategic leaders at a high level of creativity and creative thinking in order to visualize the future of their organizations, as well as determining precisely the degrees of business direction in them .The
Dr. Osama Abdul Munim ${ }^{1}$, PhD, Prof.

School of Business, Jerash University Jerash University, Jerash, Jordan

Hamzeh Alhawamdeh ${ }^{1}$, PhD, Assistant Prof.

School of Business, Jerash University Jerash University, Jerash, Jordan

success of the organizations depends on the availability of those strategic leaders with advanced entrepreneurial thought who believe in the necessity of adopting advanced technological techniques that are embodied in entrepreneurial artificial intelligence and trying to develop them. Entrepreneurial strategic leaders do not mean only those in the higher levels of management, but also the leaders in lowest ranks, as all leaders participate in orientation and strategic vision. They also participate in the development of a strategic plan that is in line with the goals of the organization and serve its interests in a technologically advanced business environment, which necessitates it in keeping pace with intellectual technological developments that are embodied here in the pioneering artificial intelligence, thus will affect the organization's policy and future strategic operations.

The entrepreneurial mindset is considered necessary for the entrepreneurial leaderships of international business organizations to try to identify the entrepreneurial opportunities that the organization can track through developing new goods and services and new markets, and it is an important factor in supporting the integration of new product design ideas, and commitment to its implementation, which ultimately leads in creating a real added value for its strategic operations locally and globally.

\section{Study problem:}

The study problem is embodied in the following main question:

- The impact of artificial intelligence techniques on the entrepreneurship of the leadership of international business organizations?

- Study hypothesis: According to the study problem, the study hypothesis is structured according to the following:

- Artificial intelligence techniques have no impact of on the entrepreneurship of the leadership of international business organizations? 
> Study objectives:

The study aims to:

- Increasing knowledge of the leaderships of business organizations about the concept and types of technological techniques innovation, embodied here in artificial intelligence.

- Identify and analyze the relationship (influence) between artificial intelligence techniques and the entrepreneurship of the leadership of international business organizations.

\section{$>$ Study Approach:}

The study relied on the Analytical Descriptive Approach for the subject of the study, and this approach is applied in many research and studies, especially those dealing with social phenomena, where a number of research and studies published in periodicals and specialized scientific journals, as well as those published on the Internet, have been reviewed. In addition to being acquainted with the international and Arab efforts to confront this phenomenon, and it was subjected to analysis and discussion in a way that serves the objectives of the study.

\section{ARTIFICIAL INTELLIGENCE SCIENTIFIC AND INTELLECTUAL CONCEPT}

A person who is close to this pioneering intellectual concept finds that this science works on the fact of understanding the nature of human intelligence by making computer programs that are capable of simulating human behavior characterized by intelligence, so the intellectual definition of artificial intelligence is embodied in the fact that it is (one of the applications of computers that is interested in building programs capable of studying and implementing repetitive activities carried out by man), Therefore, this science aims to understand the complex mental processes that the human mind performs while practicing the thinking process, and then translating these mental processes into the corresponding accounting processes that increases the ability of the computer to solve complex problems. thus, each of (Stair \& Reynolds) agree that artificial intelligence is only a study and a design of systems or devices that visualize the surrounding environment in order to act behaviors that simulate human behavior, so artificial intelligence technologies have made a great revolution in the field of information technology, since artificial intelligence is a sub-field For Computer Science, and includes the creation of smart devices and programs that work and interact like humans (Kamble and Shah, 2018). It is a commonly used name to refer to the field of science that aims to provide machines with the ability to perform functions such as logic, planning, learning and perception. Although this definition refers to "machines" in its content, it can be applied and generalized to "any kind of living intelligence", Accordingly, the meaning of artificial intelligence can be expanded to include a group of different and interlocking abilities, such as creativity, emotional knowledge and self-awareness (Perez et al., 2018) . The steady acceleration of the evolution of artificial intelligence leads strategists to restructure their businesses and their models, which supports the linking and overlapping of artificial intelligence with business processes (Soni et al., 2019), so we find( Al Sedrah ,2017) defining it as "that field of study that depicts the automated learning skill just like humans, it examines the ability to respond to some behaviors also known as artificial intelligence. While (Poola ,2017) defines it as "the development of complex, more advanced systems that have the potential to outperform humans in multiple ways.(Tyagi ,2016) believes that artificial intelligence is capable of changing human life and almost everything that relates to it, such as economics, labor, wars and communications, health services, privacy, security and even ethics, and others.

He also interpreted the specialty of artificial intelligence as the academic field that studies how to create computers and computer programs capable of performing and behaving in an intelligent manner (Elaine, 2017). Artificial intelligence is described in four different dimensions; Includes intelligence, research, business and programming. Artificial intelligence from a smart dimension requires machines to operate the way people expect to do after research and work (Carol and O'Leary, 2013).

The researchers believe that this science embodies the language of simulation between intelligent human behaviors and between computers, the goal is to reach intellectual leadership for the computing used by companies and international business organizations aiming at local and global entrepreneurship.

The importance of artificial intelligence: The importance of artificial intelligence for any company using it is embodied in the following:

(Abdul-Nour, 2005: 166), (Al-Ratimi, 2009: 78) It is embodied in the following:

$>$ A comparative method of the human method is used to solve complex problems

$>$ Deal with hypotheses synchronously, accurately and with high speed

$>$ Having a specialized solution for each problem and for each homogeneous category of problems

$>$ It works with a stable scientific and advisory level that does not fluctuate

$>$ Symbolic non-numeric data is handled through logical analysis and comparison

$>$ Raising new ideas that lead to innovation

$>$ Immortalizing human experience

$>$ Providing more than one copy of the system to compensate for the loss

$>$ The absence of feeling tired and bored

$>$ Reducing reliance on human experts

$>$ Expenditure savings and minimize human effort 


\section{ARTIFICIAL INTELLIGENCE PROPERTIES}

The most important characteristics of artificial intelligence are: (2016, Scherer).

$>$ Its use of an intellectual method similar and somewhat identical to the human method in solving complex problems, characterized by synchronization, accuracy, and high speed in receiving and dealing with hypotheses, the ability to find a solution to each problem, as well as the ability to process non-digital data of a symbolic nature.

$>$ Entrepreneurial artificial intelligence perpetuates human experiences and provides multiple alternatives to the system, allowing experts to be dispensed and compensated.

$>$ Independence and prediction: It is the ability of entrepreneurial artificial intelligence to act independently. Artificial intelligence systems are able to perform complex tasks such as building an investment portfolio, without effective human control or even supervision. There are great possibilities for the challenges and economic turmoil in the labor market caused by AI applications, and how these applications are likely to accelerate the way forward.

$>$ Monitoring: the risks that arise from the independence of artificial intelligence include not only problems of predictability but also problems of control, it may be difficult for humans to maintain control of the programmed machines to work with a large amount of autonomy, there are many problems that occur in the mechanisms, which causes Control loss: malfunction, such as a damaged file or physical damage to the input equipment; Security breach which in here the large response is shown by these applications with superior response time compared to humans. And the AI is designed with features that allow it to learn and adapt. These are the characteristics that make artificial intelligence a potential source of general risk on a scale far beyond the familiar forms of general risk that result only from human behavior.

But we find that (Bakr, 2008: 4) showed that there are other characteristics of artificial intelligence, as he saw:

Artificial intelligence has distinctive characteristics if applied within computer programming, where these systems can be described as smart and among the most important of these characteristics:

\section{Symbolic Representation}

This is one of the first characteristics of artificial intelligence programs used by companies. It deals in general with non-numerical symbols, and this is the opposite of what is known and accepted in most computers today dealing with numerical quantities and numbers.

\section{$>$ Knowledge Representation}

Artificial intelligence programs, in contrast to statistical programs, contain a method for representing information, as they use a special structure to describe knowledge. This structure includes facts, the relationships between these facts, and the rules that link these relationships within the companies applying to them.

\section{$>$ Using the optimistic experimental method}

One of the important characteristics in the field of artificial intelligence is that it focuses on Sufficient Solutions and not confirming the optimal or accurate solutions as applied in the current traditional programs.

\section{Ability to deal with incomplete data}

Artificial intelligence programs have the ability to find some solutions even if the information is not available in its entirety at the time when the solution is required and that the consequences of the lack of information integration lead to conclusions less realistic or less worthy.

\section{$>$ Ability to learn}

An important characteristic of smart behavior is the ability to learn from previous experiences and practices, as well as the ability to improve performance, taking into account past mistakes.

> Types of artificial intelligence: The artificial intelligence includes the following types: (Ajam, 2108)

- Expert systems: are computer programs that imitate the procedures of experience in solving difficult problems. Experts' expertise is transferred to expert systems for the benefit of users in solving problems. O'Brien (2000: 322) says it is a knowledge-based information system where he uses his knowledge about special and complex applications to act as a consultant to end users, as the primary purpose of expert systems is to help a person in thinking processes and not providing him with information. Thus it makes the human being wiser, not just knowledge.

- Neural networks: They are also called industrial networks that try to simulate the way the brain works (Kenji, 2013: 25). Neural networks rely on a simple look at the nerves, so the nerves are arranged in levels consisting of a large network, Network function defined from both learning and communication.

- Genetic Algorithms: The algorithm is a set of instructions that are repeated to solve a problem. Genetic refers to the behavior of algorithms that can resemble the biological processes of evolution. (O'Brien, 2000: 339-340) defines it as solution methods that help create solutions to specific problems using methods compatible with their environment, and is programmed to work in the way a person solves issues by changing and reorganizing component parts using methods such as reproduction, transformation, and selection Naturally, thus providing us with research methods for all possible combinations of numbers to determine the correct non-numerical variables that represent the best possible structure of the problem and are useful in cases where thousands of solutions are possible and must be evaluated to produce an optimal solution. 
- Intelligent Agents: It is a knowledge-based experience system implanted within computer-based information systems or its components to make them smarter. It is an end-user program or method for accomplishing events. (O'Brien, 2000: 320) argues that an intelligent agent uses its stored knowledge base about a specific person or process to make decisions and accomplish tasks in a way that achieves user goals.

We find that according to (Hussain, 2018), the most important types of artificial intelligence are embodied in the following specifications:

- Narrow artificial intelligence: it includes part of the tasks, that specializes in one area, for example, that which the visitor performs on chat programs, and individual voice response services.

- Artificial General Intelligence: Artificial general intelligence includes tasks at the human level that operate without human participation, for example, selfdriving cars, a self-parking system, and a self-insurance system.

- Super artificial intelligence: artificial intelligence that may exceed the intelligence of humans.

$>$ The most important motives of adopting artificial intelligence technologies by leaders of international business organizations:

The researchers believe that in order for the leadership of entrepreneurial organizations willingness to frame the adoption of artificial intelligence applications, it is necessary to employ a set of indicators that can be counted as starting points and then pillars that can be used to stimulate the adoption process and determine its success, and these indicators were represented as follows:

- The power of motivation towards technical developments: Motivation is the force that drives and excites the working individual to accomplish the tasks in the best way by satisfying the needs and securing material and moral desires.

- The desire for technical excellence: This desire is the result of a strategy pursued by contemporary organizations in a manner that secures its uniqueness with certain technical characteristics in an effort to secure excellence.

- The availability of support by decision-makers: Positive reinforcement leads to the liberalization of the behavior of the working individual and in a manner that stimulates him to work and thus raising the level of its performance. This requires analyzing the work situation and determining the causes and causes, and here is a necessity to say that leaders must make meanings in an organization as they seek to Make money and support any new ideas.

- Fear of being left behind by others: The seriousness of organizational trends to face any challenges may raise fears among administrations, which leads them to keep abreast of developments in order to avoid cases of lagging behind, bearing in mind that these fears are just as an entry point for precaution and hedging, as they may be a cause of chaos and slippage in the manner that Lead to frustration.

\section{$>$ High performance organizations HPOs:}

It is a new type of organization designed with targets that are perceived by members of the organization to create organizational advantages to produce high-performance outputs.( Schermerhorn et al. 2004: 25) see them as organizations that are responsive to market demands by strengthening their internal susceptibility, and placing them primarily in the human element. As for (Robbins \& Judge, 2008: 25) they said that they are organizations that are ready to deal with the changing environment and are ready to be networked organizations and promote work towards positive organizational behavior. (Jamal and Taher, 2017)

In order for high-quality entrepreneurial organizations to reach the intellectual level that will drive global entrepreneurship, they must work according to a developed intellectual system, and they must, above all, work to provide the following:

Creative behavior of business organizations: It is the distinctive behavior that an individual practices in a workplace within the organization, and does not necessarily result in new results, services, or goods. It is a behavior that precedes creativity in its final form. Creative behavior was measured through the following elements:

- Presenting proposals and new ideas and submitting it by searching for what is new and avoiding routine.

- Providing innovative solutions to problems, which shows the individual's ability to provide innovative solutions to the problems he is going through.

- The ability to change, and expresses the pursuit of new ideas and their development, and the desire to enter non-specialized fields.

- The spirit of risk: is the individual's desire to take risky actions.

- The relationship of colleagues and superiors: is the development of personal relationships with workers in the organization and the freedom and desire to be acquainted with the proposed ideas and their multiplicity and amend or encourage them to provide the best.

\section{$>$ Intellectual leadership of the international business organization: (Gulab and Grimakh, 2018)}

Entrepreneurship is a phenomenon associated with innovation, creativity, discovering new opportunities and initiating the adoption of it as well as taking risks and dealing with mysterious circumstances, and the need for achievement that leads to creating wealth and growth, such as adding new services or improvements to the product. The beginnings of the term entrepreneurship were through (Hamphill \& Coons), Where we have shown that they are comprehensive attempts that have shown that leadership behavior in business organizations is a pioneering dimension. He explained that the entrepreneur is the person who has the ability to take the risk by buying goods or part of them at a certain price, and selling them in order to obtain profit, whether they are new goods, or old ones. 
Therefore, the word entrepreneur appeared in the French language for the first time (entre), which is derived from French words meaning (between-and-taker), and that the entrepreneur takes a position between the supplier and the customer. Likewise, the ability to take risks and work to transfer resources from a lower level to a higher level of productivity (Peggy, 2000: 14).

The word entrepreneur is given to those who organize expeditions or lead military campaigns, or run large projects such as building forts, castles and bridges, and also (Histrich et al., 2005: 10) clarifies that an entrepreneur is someone who has the ability to be creative and take the risk in providing products And new services.

But the question now is what are the traits of entrepreneurs for business leaders.?

Attributes of entrepreneurs: The success of an entrepreneur depends to a large extent on the nature of his personality and behavioral characteristics, and as (AlAmiri and Al-Ghalibi, 169: 2007)see, the entrepreneur is distinguished by his special features, such as the desire to establish his own kingdom, the desire to succeed, creativity and innovation, as for (Bolton \& Thompson., 2000: 170) they defined entrepreneurial traits as the ambition at work, customer focus, persistence despite the failure, It was reported from (Hitt et al., 2002: 112) that among the characteristics of entrepreneurs: innovation, ability to take risks, orientation towards change and access to competitive advantage through competition, and the entrepreneur differs from others in knowing the priorities and the balanced status of profitable operations during his evaluation of future opportunities, and determining The value of risk by reducing challenges and facing the market by improving its competitive position through developing technology for its products in order to maximize the characteristics, benefits and services, which generates a conviction among customers that there is a difference in these products from other competitors. Therefore, researchers believe that the entrepreneurial role of business organizations is embodied in the following:

- Creating new markets.

- Discovering new sources of materials to improve their business.

- -Moving capital resources by creating new services, as they have innovation and self-confidence that enables them to skip these steps.

- -Introducing new technology, new industries and products away from being innovative and taking risk with absolute responsibility.

- -Creating new job opportunities, as such opportunities have effects and impacts that accelerate the growth of the economy as a whole.

\section{> The leadership dimensions of international business organizations are as follows:}

Creativity: Creativity is needed by all organizations of all kinds, as the best organizations are the ones that have the ability to be creative and the best managers and business leaders are those who can provide the appropriate organizational climate to help members of the organization to use their creative talents completely (Al-Kalkawi, 2004: 21), (Al-Amiri and Al-Ghalabi 2008: 441) asserts that creativity is not a single process that takes place in one quick moment in time, but rather a series of successive phases that depend on one another, especially when it comes to radical creativity, which means a fundamental change in the characteristics of the product or an entirely new production.

The strategic vision: The strategic vision is one of the most important things that the entrepreneur actually possesses, as the entrepreneur leader is the one who has the vision and inspiration, it is he who has a clear sense of the future and a great understanding of the necessary procedures. This vision is associated with the organization's mission and the process of formulating and reviewing its goals. It prepares the organization to see the future and helps create a long-term trend linked to the organization's strategic goals.

Initiative or proactive: This is embodied in the organization's ability to know opportunities when launching products to the market and obtain information about the past, present, and future status. And Morris et al (2002: 5) showed that proactivity or pre-eminence is related to the following concepts:

- Seizing opportunities in the market that are not related to the current operations

- Introducing new and rare products different from other competitors

- Strategic planning for operations that are in the application stage during the service life.

Investing opportunities: Investing opportunities is one of the most important features of entrepreneurial leadership for organizations in the current era, as the success of entrepreneurial organizations did not come as a surprise, but rather was the result of investing opportunities through continuous monitoring of the needs and desires of the guests and that the evaluation of opportunities and their investment is done through the skills that individuals enjoy and achieve the various goals and advantages of the competitive environment as well as knowing the reason for the opportunities, whether they came as a result of technological changes or as a result of competition

The Risks: The risk is defined as: the condition that results in damage or loss, and the risk in the business world is the situation that affects projects, which causes them to lose or bankruptcy or impede their growth (Al-Mansour, 2003, 390), as risk is one of the most vital problems affecting organizations an effective impact, and it defined as "the probability of receiving a reward or achieving returns in the event of a successful project work plan" (Robert \& Meier, 2001: 3)

The researchers believe that in order for the leaders of business organizations to reach the pioneering situation that develops from its serious strategic thinking, which will lead towards achieving the added value of its strategic 
operations that the leader who owns it should apply strategic entrepreneurial thinking by:

- Strategic thinkers have the ability to build long-term goals and objectives for their organizations, and this means their ability to define paths and ways to achieve the organization's mission and vision.

- Strategic thinkers are characterized by environmental sensing, as they have the ability to seize the opportunities available in the external environment and avoid potential threats. As well as the need for strategic thinkers to be distinguished by having insight and study in assessing the strategic position of their organizations

- The strategic leader benefits from information technology data, knowledge management and strategic information systems and has the ability to analyze and interpret data and information on past and current events to reach an in-depth understanding about the strategic position of their organization and to take appropriate strategic decisions for that must have high skill in choosing the strategic alternative to meet the strategic position of their organization, They have the ability to evaluate alternatives by comparing the advantages and disadvantages of each and the justifications for applying each of these alternatives

- The need for strategic leaders to have the skill to allocate available resources and capabilities and use them efficiently and effectively in line with the organization's entrepreneurial strategic goals.

- The necessity of strategic leaders to have the ability to harmonize the organization and its surrounding environment by taking into account the interests of stakeholders, and this is called in entrepreneurial management concept as the social responsibility, which is one of the factors affecting building of the organization's strategy. (Ibrahim, 2019)

- The strategic thinker has the ability to keep pace with managerial globalization by constantly observing global environmental factors and determining the extent of their impact on the local environment in general and the organization in particular.

- Strategic leaders have the power of intuition, meaning that he has the ability to relate ideas and facts and mix them with each other to form a new creative idea and conceptualize the organization's strategic options.

- The thinker has the foresight and insight. he has the ability to gain insight into the current state of the world and its development in advance, and to identify opportunities and threats facing the organization. Moreover, the strategic thinker possesses personal characteristics that distinguish him from others, such as caring for workers, striving to develop their competencies and adopting risk to a high degree.
$>$ The reality of the impact of artificial intelligence techniques on the entrepreneurship of the leadership of international business organizations:

Entrepreneur leaders, according to the researchers, are expected to possess the qualities of intellectual stimulation, which is important in entrepreneurial leadership because it leads to supporting subordinates in order to abandon old habits of thinking and be creative and innovative. and for entrepreneurial leaders to be willing to change the the existing situation of their organizations through major change events when this is necessary and to be beneficial in the long run to the success of the organization (Burns, 2004: 78) and they will be able to influence and motivate their followers to do more than expected, using their ability to empower and encourage others to achieve a shared and entrepreneurial vision. When the leader leads by providing intellectual stimulation, he encourages his followers to challenge the existing situation and abandon old methods of doing things. and when they are encouraged to reformulate dependent issues and problems and meet intellectual curiosity, they will use imagination and are maneuvered with ideas and solutions.

Under these circumstances. Workers are more likely to be interested in focusing on their goals than concerns, and external anxiety. Therefore, the researchers believe that the technical environmental challenges are represented in a group of threats and risks facing entrepreneurial organizations and leaders, which requires those leaders to prepare plans to confront these threats, taking into account all available and facilitating opportunities, knowing that these threats are the result of a series of environmental interactions Surrounding these organizations and their leadership, as well here the features of artificial intelligence are clarified and the creative impact of it considered as an auxiliary factor for those leaders in creating the correct strategic thinking for it to reach the added value of its strategic operations in the field of confronting environmental challenges at the local and global levels. Here, the study hypothesis will be rejected and the alternative hypothesis will be accepted, except that there is an effect of artificial intelligence in creating the correct strategic thinking for the entrepreneurial leaders of business organizations to reach the added value of its strategic operation.

The researchers suggest the following model, which was developed by the study (O, Shannassy ,2000, Hitt etal ,2005), which expresses The reality of the impact of artificial intelligence techniques on the entrepreneurship of the leadership of international business organizations in arriving at the added value of their strategic operations: 


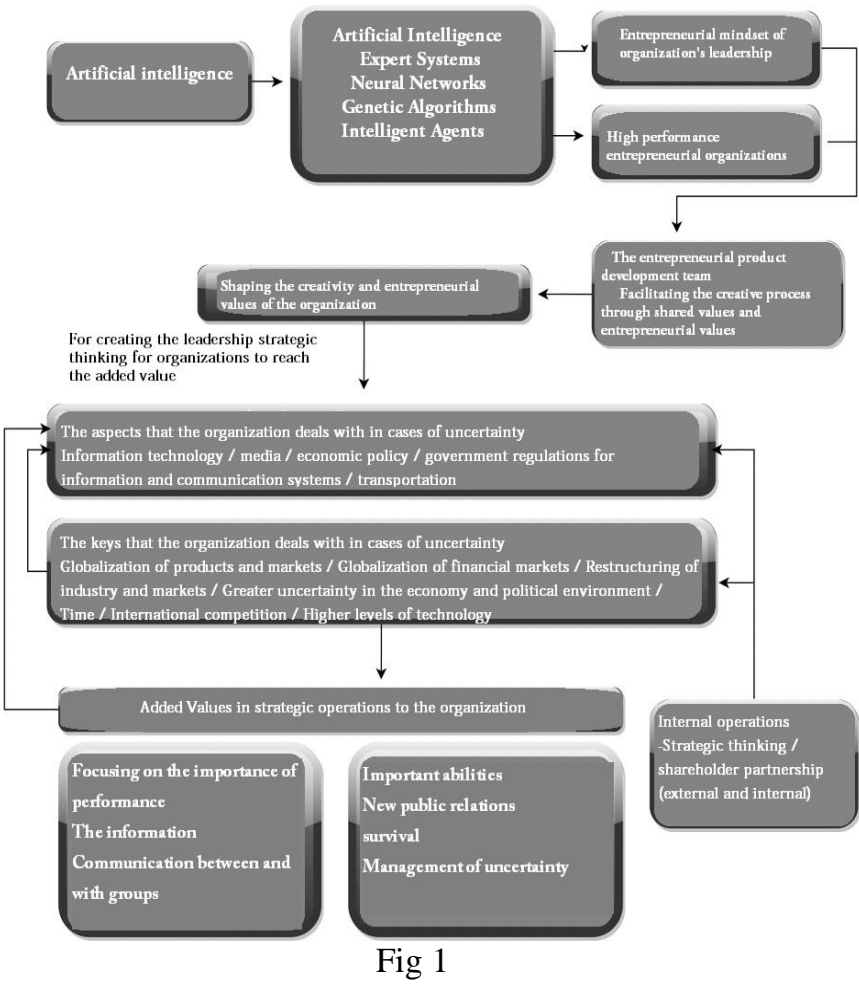

Explanation of the proposed research model:

First: Owning an organization that has faith in the outputs of artificial intelligence systems and their pioneering impact on them: they will consider the types of artificial intelligence that are embodied in the following:

- Expert systems

- Neural networks

- Genetic algorithms

- Intelligent Agents

- Narrow artificial intelligence

- Artificial General intelligence

- Super artificial intelligence

Second: The use of these systems shall be by:

(High performance organizations HPOs) aspiring to global entrepreneurship: It is a new type of organization designed with targets that are perceived by members of the organization to create organizational advantages to produce high-performance outputs. and they are considered an organization that are ready to deal with the changing environment and are ready to be networked organizations and promote work towards positive organizational behavior.

Third: These organizations need entrepreneurial leadership: the dimensions of which are embodied in:

- Creativity

- The strategic vision

- Initiative or proactive

- Investing opportunities

- Taking Risk
Fourth: Entrepreneurial leadership must possess strategic thought to achieve added value by:

- Strategic thinkers have the ability to build long-term goals and objectives for their organizations

- having the insight and the study in estimating the strategic position of their organizations.

- Strategic thinkers are characterized by environmental sensing, as they have the ability to seize the opportunities available in the external environment and avoid potential threats.

- The strategic leader benefits from information technology data, knowledge management and strategic information systems

- high skill in choosing the strategic alternative to meet the strategic position of their organization

- The need for strategic leaders to have the skill to allocate available resources and capabilities and use them efficiently and effectively in line with the organization's entrepreneurial strategic goals.

- The necessity of strategic leaders to have the ability to harmonize the organization and its surrounding environment by taking into account the interests of stakeholders, and this is called in entrepreneurial management concept as the social responsibility

- The strategic thinker has the ability to keep pace with managerial globalization by constantly observing global environmental factors and determining the extent of their impact on the local environment in general and the organization in particular.

- Strategic leaders have the power of intuition, meaning that he has the ability to relate ideas and facts and mix them with each other to form a new creative idea and conceptualize the organization's strategic options.

- The thinker has the foresight and insight. he has the ability to gain insight into the current state of the world and its development in advance, and to identify opportunities and threats facing the organization.

- The strategic thinker possesses personal characteristics that distinguish him from others, such as caring for workers, striving to develop their competencies and adopting risk to a high degree.

Fifth: The mechanism that high-quality and leadership organizations deal with to achieve added value, and by taking into consideration the following:

- Aspects in which the organization deals with in cases of uncertainty:

Information Technology

The media

Economic policy

Governmental regulations for information and communication systems

Communication systems

Transportation 
- Keys that the organization deals with in the cases of uncertainty:

Globalization of products and markets

Globalization of financial markets

Restructuring of industry and markets

Greater uncertainty in the economy and the political environment

Time

International competition

Higher levels of technology

- Establishing a strong relationship between all those interested in the affairs of the organization by taking:

Strategic thinking

Shareholders' Partnership ((external and internal))

Sixth: The values added in the strategic operations to the organization, and shall be by:

- The important capabilities of an entrepreneurial organization are through: survival, new public relations, managing uncertainty

- Focusing on the importance of the entrepreneurial organization: - Performance, information, and communication between and with groups.

\section{CONCLUSION}

There must be a level of readiness among the entrepreneurial leaders of international business organizations regarding the adoption of artificial intelligence techniques, as each technique of artificial intelligence has pioneering implications for the efficiency of organizations and leaders affiliated to it, and this is provided if there is a real motivation stemming from the feeling of those leaders of the importance of those Applications and techniques in creating the correct strategic thinking for leaders of business organizations in order to reach the added value of their strategic operations, which aspires to reach the entrepreneurial leadership at the local and global levels.

This would be the researchers' view by paying attention to the distinguished mental capabilities that these leaders possess as intellectual capital that contributes effectively to achieving creativity and seizing new opportunities for their organizations, while investing in the organizational characteristics that enhance the pioneering role of the strategic leadership represented in generating innovative and new initiatives related to applications and techniques of artificial intelligence, Through initiative and adoption of the calculated risk that ensures building a sustainable competitive advantage that cannot be matched with the services provided by other organizations working in the same field, which requires harmony and interconnection between the capabilities of strategic thinking, and the influential leadership personality, and in such a way as to ensure the conversion of the core resources into capabilities that accumulate over time, in order for entrepreneurial organizations to achieve creativity and provide exciting value of services, and thus achieve local and global excellence.

\section{REFERENCES}

[1]. Abdel Nour Adel .Basics of Artificial Intelligence, 1st Edition, Al-Faisal Cultural House, Riyadh. 2005

[2]. Ajam, Ibrahim Muhammad Hassan, Artificial Intelligence and its Implications for High Performance Organizations An Exploratory Study at the Ministry of Science and Technology Journal of Administration and Economics, University of Baghdad, forty-first year - the number one hundred and fifteen 91-93, 2018.

[3]. Al-Amiri, Saleh Mahdi, Al-Ghalabi, Taher Mohsen, " intellectual Capital: The New Competitive Advantage of Construction Organizations in the Light of the Digital Economy", The Eighth International Scientific Conference, Al-Zaytoona University - Amman. 2007.

[4]. Al-Amiri , Saleh Mahdi Mohsen and Al-Ghalabi Mohsen Mansour. Administration and Business, Wael Publishing House, Amman Jordan. 2008.

[5]. Al-Kalkawi, Ahmed Hameed "The relationship between organizational climate and organizational creativity and their effect on achieving competitive advantage - an applied study in a sample of Iraqi commercial banks", Master Thesis in Business Administration, College of Management and Economics, University of Qadisiyah. 2004.

[6]. Al-Rutaimi Muhammad Abu Al-Qasim Applications of artificial intelligence, University of Al-Zawia . the seventh of April, - Libyan Society for Artificial Intelligence, Tripoli, Libya. 2009.

[7]. Al-Sedrah, M.K ., Artificial Intelligence, Advanced Analysis and Design: CNIT 380, AUM. 2017.

[8]. Bakr Munther Noman. Artificial Intelligence and Information Technologies, The First Scientific conference Amman Jordan. 2008.

[9]. Bolton, B., Thompson, J. Entrepreneurs, Talent, Temperament, Technique, Butterworth Heinemann: Oxford. 2000.

[10]. Burns, P. Corporate Entrepreneurship: Building an Entrepreneurial Organisation. New York: MACMILLAN. 2005.

[11]. Carol E. B, O'Leary D. Introduction to artificial intelligence and export system. 2013 ;(Retrieved on 6/10/2017),

Available:http://www.mbsfile03.uscredu/dialtalmeasu res

[12]. Elaine R. Overview of AI and its Application Area; (Retrieved on 20/09/2017),Available:http://members.90n.at/frankstei n/frankeinstein-novelhtm. 2000.

[13]. Gulab, Ehsan Dish and Grimakh, Hamida Ghajir. The Impact of Entrepreneurial Leadership on Innovative Performance, Field Study in a number of private colleges in the provinces of the Middle Euphrates Iraq. Iraqi Journal of Administrative Sciences) (Volume 14) No. 55, Karbala University, Iraq, p. 217. 2018.

[14]. Histrich ,Robert .D and Michael. Peters," Entrepreneurship", sixth edition , Mc Grow - Hill Higher Education. 2005 
[15]. Hitt,Miechael

A.,

Ire land,R.Duane,\&Hoskisson,Robert $\quad$ E., ,Strategic management : competitiveness \&Globalization concepts",Australia.Thomson,p:64. 2005.

[16]. Hussain, K. Artificial Intelligence and its Applications goal, International Research Journal of Engineering and Technology (IRJET), Vol.05, Issue 01. 2018.

[17]. Ibrahim, Muhammad Khalil. The effect of the absence of strategic thinking in the lack of development of the reality of environmental tourism in the marshes of Maysan Governorate, Wasit Journal for Humanities, Wasit University, No. 42 Volume 15, Central Iraq, 211-240. 2019.

[18]. Jamal Dina Hamid and Taher Abdul Karim Mazal, The Impact of Electronic Knowledge on Entrepreneurial Leadership - An Applied Study of a Sample of Travel and Tourism Companies in Baghdad City Journal of Administration and Economics, University of Baghdad, Volume 40 - No. One hundred and Ten, pp. 361 362. 2017.

[19]. Kenji Suzuki, "Artificial Neural Network: Architectures and Applications", McGraw-Hill/Irwin, New York. 2013.

[20]. Morris, M. H., Schindehutte, M., \& LaForge, R. W., Entrepreneurial marketing: A construct for integrating emerging entrepreneurship and marketing perspectives. Journal of Marketing Theory and Practice, 10(4), 1-19. 2002.

[21]. O'Brien, A. James, "Introduction to Information Systems, Essentials for the Internetworked Enterprise, 9/d., McGraw-Hill/ Irwin Inc. 2000.

[22]. O,Shannassy,Tim ,"Models and methodology to study strategic thinking in Australian public companies, Rmit Business",p:5. 2000.

[23]. Peggy, Entrepreneurship, Second Edition, Pearson Education Company, New Jersey. 2000.

[24]. Perez, J. A., Deligianni, F., Ravi. D., and Yang, G.H.,. Artificial Intelligence and Robotics, UK-RAS Network, UKRAS.ORG. 2017.

[25]. Poola, I.. How Artificial Intelligence in Impacting Real Life Every day, International Journal of Advance Research and Development, Vol.2, Issue10. 2017.

[26]. Robbins, s., \& Judge. "Organizational behavior “, 13/d., Upper Saddle River, NJ: Pearson. 2008

[27]. Robert enge \& Meier, Volker, "y2002i3p433447.html"Why cities should not be subsidized," Journal of Urban Economics, Elsevier, vol. 52(3), pages 433-447, November. 2002.

[28]. Schermerhorn, J.R., Hunt, J.G.,\& Osborn, R.N.,’Core Concepts of Organizational behavior", Hoboken, NJ: John Wiley \& Sons. 2004.

[29]. Scherer, Matthew U. . Regulating Artificial Intelligence Systems: Risks, Challenges, Competencies, and Strategies, Harvard Journal of Law \& Technology, Vol. 29, No. 2. 2016

[30]. Kamble, R., and Deepali Sh . Applications of Artificial Intelligence in Human Life, International Journal of Research - Granthaalayah. 2018, Vol.6 (Iss.6).
[31]. Soni, N., Sharma, E., Singh, N., and Kapoor, A.,. Impact of Artificial Intelligence on Businesses: from Research, Innovation, Market Deployment to Future Shifts in Business Models, Journal of Business Research - Elsevier for consideration. 2019.

[32]. Stair, Ralph M. and George Reynolds. Fundamentals of Information Systems. Thompson Course Technology. USA. 2006, www.ivsl.org.

[33]. Thompson, J.,R.,\&Etrich And ,S.,A, Strategic Management : Concepts \& Cases " 12ed ., Mcgraw,Hell,Irwin, U.S.A. 2001.

[34]. Tyagi, Amit. Artificial Intelligence: Boon or Bane?, SSRN Electronic Journal, DOI: 10.2139/ssrn.2836438. 2016 